\title{
Machine learning of the mineralogical and chemical constituents' influences on carbonation efficiency
}

Luqman Abidoye ( $\sim$ luqman@imco.edu.om )

IMCO: International Maritime College Oman https://orcid.org/0000-0002-1938-6391

\section{Habeebllah Oladipo}

International Maritime College Oman

\section{Research Article}

Keywords: carbonation, machine learning, mineralogical, storage, rock

Posted Date: August 11th, 2021

DOl: https://doi.org/10.21203/rs.3.rs-699283/v1

License: (9) This work is licensed under a Creative Commons Attribution 4.0 International License. Read Full License 


\section{Abstract}

Cheap and efficient computational tool is needed to understand the influences of rock's mineralogical and chemical constituents on the mineral carbonation efficiency. This work employs machine learning technique to learn some subtle contributions of minerals and technical parameters to carbonation yields in earthly materials. After training different configurations of Artificial Neural Network models, statistical appraisal shows that ANN[17-4-1] possesses the best performance criteria. Using this best-performing network, it was found that carbonation efficiency becomes lower as the particle size increases with maximum effects of size change giving up to 88,180 and $289 \%$ reductions in carbonation efficiency corresponding to 10,20 and $30 \%$ particle size increases, respectively. The simulation further highlights that the effects of particle size on carbonation efficiency can be overcome or, at least, reduced, by prolonging the duration of the carbonation. The study shows that there is optimum level of increase in the calcium amount to yield increased carbonation efficiency, following which the marginal increase in \% of calcium continue to result in decrease of efficiency. There is gradual rise in efficiency as the $\%$ of silica and iron increase in the minerals, with up to $1541 \%$ rise in efficiency at $30 \%$ increase in iron content. This is connected to the relatively higher level of magnesium in the sample considered. It was found that the high temperature $\left(>100^{\circ} \mathrm{C}\right)$ combined with high pressure ( $>10$ bars) favours increased efficiency with rise in $\mathrm{pH}$ value. Similarly, low temperature $\left(<100^{\circ} \mathrm{C}\right)$ with low pressure $(<10$ bars $)$ increased efficiency with rise in $\mathrm{pH}$ value. On the contrary, low pressure with high temperature yields reverse trends in efficiency for increase in $\mathrm{pH}$. Pressure, carbonation time and temperature, all have positive effects on carbonation efficiency. But, curiously, at very high original carbonation efficiency, e.g., above $50 \%$, reverse trend was predicted by the ANN model for temperature rise. This may mean that at very high carbonation level, it is of no benefit to raise the temperature further, as this may lead to decarbonation or desorption of $\mathrm{CO}_{2}$ in the medium. This study is among the first set of publications, in the open literature, to utilize the concept of machine learning to predict and forecast the carbonation efficiency of rock materials based on mineralogical contents and experimental conditions.

\section{Introduction}

Mineral carbonation is one of the most important methods to sequester $\mathrm{CO}_{2}$, having the advantages of permanent storage and abundant mineral resources (Wang et al. 2019). It is particularly important as a cheaper and easier means of combatting the rising $\mathrm{CO}_{2}$ level in the atmosphere. Mineral carbonation offers the benefits of permanent and safe storage (Sanna et al., 2014; Pasquier et al., 2014; Sun et al., 2008) with opportunities for making use of ubiquitous earthly minerals (Xi et al., 2016; Polettini et al., 2016; Song et al., 2016), either as whole materials or as mine wastes (Hasan et al., 2018).

Strongest attraction to mineral carbonation is the stability of the final products, which are mainly silicates and carbonate (Wang et al. 2019; Wang et al. 2018) over a geological period of time (Matter et al., 2016). According to Martinez et al. (2014), auspicious minerals for carbonations, which are also abundant in earth's crust, are silicates of $\mathrm{Mg} / \mathrm{Fe} / \mathrm{Ca}$. Need for climate change mitigation is much more needed now 
than at any other time in history. This need can be supported by intensifying the process and advancing the technologies of mineral carbonation. So, all measures must be prepared towards meeting the United Nations' targets of limiting global warming to well below $2^{\circ} \mathrm{C}$ and to actively pursue a $1.5^{\circ} \mathrm{C}$ limit (Hansel et al. 2020).

To improve the carbonation potentials of mineral rocks and other earthly materials, potent mineralogical and chemical constituents must be understood and selected under optimal experimental conditions to arrive at the desired yield of carbonates. According to Huijgen et al. (2006) and Sanna et al. (2014), carbonation rate is controlled by the diffusion of $\mathrm{Ca}^{2+}$ through the solid Si-rich layers in silicate minerals. This points to the fact that porosity and surface area will play a role in carbonation efficiency. O'Connor et al. (2005) found that elevated conditions of pressure and temperature can enhance the carbonation process in the presence of bicarbonate ions. Mineralogical and chemical composition were of great importance for the mineral carbonation process (Ramli et al. 2021). Wang et al. (2019) found that the decrease in particle size, increase in temperature and ionic strength in solution dramatically enhance the carbonation. Ramli et al. (2021) indicates that divalent cations, pH and particle size are important parameters to consider in the carbonation yield. The authors found that the rise of temperature from 80 $\circ \mathrm{C}$ to $150-200 \circ \mathrm{C}$ resulted in a higher Fe and Ca carbonation efficiency. The optimum conditions for the occurrence of mineral carbonation is greatly dependent on the experimental conditions and material properties (Ukwattage et al. 2017).

The above discussions show that there are myriads of factors and elements to be considered to arrive at optimal carbonation efficiency. Improved selection, combination and understanding of these factors, for optimal carbonation yields, are not easy to resolve without the assistance of computational tool. As a result, this work is employing machine learning technique to learn some subtle contributions of minerals and technical parameters to carbonation yields in earthly materials. The work is novel in the use of machine learning for dissecting the influences of mineralogical and chemical constituents of rock materials on carbonation efficiency. This study is the first or among the first set of publications, in the open literature, to utilize the concept of machine learning to predict and forecast the carbonation efficiency of rock materials based on material contents and experimental conditions. Machine learning has been employed to study the carbonation depth in recycled aggregates (see, e.g., Nunez and Nehdi, 2021; Chowdhury et al., 2016; Taffese et al., 2015; Akpinar and Uwanuakwa, 2016) and fly-ash blended concrete (Uwanuakwa, 2021). All these publications applied machine learning technique to concrete carbonation but not mineral carbonation. Ramli et al. (2021) used experimental investigations to find that mineralogical and chemical composition were of great importance for the mineral carbonation process. But, the authors did not perform any mathematical modeling.

\section{Machine Learning- Artificial Neural Network (ANN)}

Recently, machine learning has evolved to be a cheap and advanced tool of studying and modelling scientific, natural, economics and even socio-political processes. Machine learning tools have the 
advantages of adaptability to social and scientific system. Its attraction to scientists and researchers often lies in its common non-proprietary status together with the proliferation of applications and education platforms. Thus, it is cheap and ubiquitous to access. The tools of machine learning include Support vector machines (SVMs) and supervised machine learning techniques, such as artificial neural networks (ANNs), which offer better prediction than linear models (e.g., multiple linear regression (MLR) and time-series models such as autoregressive integrated moving averages (ARIMA)) (Freeman et al. 2018; Liu 2007; Vlachogianni et al. 2011; Zickus et al., 2002). Another arm of machine learning is the Deep learning, with advanced mathematical tools and protocols to analyze and model datasets. Deep learning involves advanced architectures such as recurrent neural networks (RNNs) and convolutional neural networks (CNNs) (Goodfellow, Bengio, and Courville 2016). CNN is a type of Deep learning used for image classification.

ANN does not require assumptions about the data apriori and eliminate the need for initial weighting input data. These are major benefits of ANN (Gardner and Dorling 1998). Popular architecture in ANN is the feed forward Neural Network (FFNN), consisting of an input layer, a hidden and an output layer. Each layer is connected to a node that transforms weights and biases assigned to preceding layer using embedded mathematical equations, which often involve summation of the weighted inputs of preceding layers, often with a bias. The summation is then transformed with a nonlinear activation function, $\sigma$, as shown below:

$$
y=\sigma(w x+b)
$$

where ' $x$ ' is a vector of input values, ' $w$ ' is an array of weights for the connections between the previous layer and the current layer, and ' $b$ ' is a bias value. Common activation functions include the sigmoid, tanh, and 'relu' functions. A general property for activation functions is that they normalize the output and have a continuous first-order derivative that can be used during the back-propagation training process (Goodfellow et al., 2016).

Artificial neural network (ANN) is a system of electronic processing units, called neurons, which are technically arranged to mimic the behavior of biological neural networks. The neurons are processors, each or group, with specific algorithms to learn, manipulate and predict patterns inherent in a set of data or process, through the deciphering of complex non-linear relationships between the listed input and output parameters of system under study.

Learning process in ANN involves the manipulation of inputs vector with assignments and operations of weights at the neural interconnections, in accordance with the perceived patterns and trends in output vector. This procedure is continued over a cycle of epochs with systematic adjustments of weights and biases, to minimize the error values between the predicted and the actual outputs. The number of hidden layers vary from a single (basic perceptron) to several layers (such as those of the Deep Neural Networks). During training, the network automatically adjusts the values of the weights and biases 
assigned to the neurons using one of several learning algorithms in order to reduce errors between the supplied and predicted outputs (Shetty and Chellam 2003; Wang 2006; Zabihi et al. 2011).

Feedforward and feedback networks are common in the ANN operation. In Feedforward network, neurons of hidden layers only get inputs from the preceding layer and feed outputs to the succeeding layer. On the other hand, feedback networks allow two way connections between layers of neurons thus establishing a cyclic directed graph. Feedback networks also called recurrent networks, is the most common type in engineering applications (Arpat et al. 1998; Nowroozi et al. 2009; Saeedi et al. 2007). ANN also utilizes the ability of some transfer functions for intermediate transformation of the preprocessed data. Examples of these transfer functions are log-sigmoid, tan-sigmoid as well as linear functions (Boroumand and Baziar 2005; Haykin 2009; Khataee and Kasiri 2010).

The works of Abidoye and Das (2015) as well as Hanspal et al. (2013) demonstrated how ANN can be used to explore complex interrelationships among parameters in process systems. Considering the myriads of factors that can affect the carbonation efficiency, ANN possesses the ability to understand the complex relationship among the interacting factors of rock minerals, chemical phases and process conditions to predict the outcome effectively.

This work aims to demonstrate the feasibility of utilizing ANN to understand the patterns and the conditions of contribution by each element of carbonation process in geological media from the minerals and chemical phases, process conditions and their various combinations. The study will be among the first set of publications, in the open literature, to utilize the concept of machine learning to predict and forecast the carbonation efficiency of rock materials based on material contents and experimental conditions

\section{Methods}

The methods of this investigation involved sourcing of reliable data from literature with which different configurations of ANN were trained. The performances of the trained networks (ANNs) were then assessed to arrive at the best-performing ANN configuration. This best-performing configuration was then used to predict and forecast carbonation efficiency based on the influences of mineralogical and chemical constituents of rock materials as well as the experimental conditions.

\section{ANN Configuration}

In this work, different ANN configurations were trained and evaluated to arrive at the best network for predicting mineral carbonation from rock characteristics and process conditions. The networks were configured with Feedforward structure while back-propagation algorithm was employed for the purpose of training. The ANN structure was in the form ANN[X-Y-Z] where ' $X$ ' is the number of input variables; ' $Y$ ' is the number of neurons in the hidden layer and ' $Z$ ' is the number of variables in the output layer. Different ANN configurations were tested using the approaches followed by Hanspal et al. (2013) and Abidoye and 
Das (2015). Networks were created using single layer alone but with different number of neurons in each of the layers. The number of neurons was progressively increased for different configuration. The simulation platform was MATLAB (MathWorks, 2016). To implement the simulation procedure in MATLAB, program files were prepared with lines of code to create, train, validate and test the network as well as to generate the goodness of fit parameters of the data points using correlation coefficients (R2) and mean square error (MSE). In the script, the 'While loop' procedure was used. The criteria of > '0.99' coefficient $\left(R^{2}\right)$ was set for the loop with twenty rounds of training for each configuration. The network with each configuration was subjected to rounds of training until satisfactory performance was obtained. So, if after twenty rounds of training, the criteria was not satisfied, the training was stopped and the training of the next configuration began. The program divides the dataset randomly into 60,20 and $20 \%$ corresponding to the data for training, validation and testing, respectively. In the training process, epochs of 200 was used as the stopping criterion. Epoch is the maximum number of times all of the training sets are presented to the network. Thus, the training stops if the maximum number of epochs is attained. The network trainings thus stopped when the number of iteration exceeded the stated number of epoch or other criteria are satisfied. At the end of the training, network object is generated with indication of the best validation performance. The result from the training giving the best performance was then selected for each configuration, for comparisons and selection.

\subsection{Data Sources and Processing}

The data for this work were obtained from the carbonation data contained in the works of Wang et al. (2019) and Ramli et al. (2021). The work of Wang et al. (2019) is an experimental investigation of fundamental factors influencing mineral carbonation, using detailed kinetics of the process. Their work presents a typical example of detailed fundamental factors affecting mineral carbonation. On the other hand, the work of Ramli et al. (2021) investigates the mineralogical and chemical composition of iron ore mining waste alongside the effects of particle size, temperature, and $\mathrm{pH}$ on carbonation efficiency. So, the combination of these works present good substances of mineral carbonation. Data mining software, CurveSnap_V1.0, was used to extract the data from the plots contained in the above publications.

Conditions of the experiments were also noted meticulously. Overall, 17 variables were extracted with total of 4428 data points. The variables and the summary of their statistical variation are shown in Table 1.

\section{ANN model performance criteria}

The criteria used to evaluate the performance of different ANN model configurations listed and explained below. Eqs. (2) and (3) are mathematical representations of detailed statistical analyses used to evaluate the performances of various ANN configurations that were trained in this work.

\section{Mean squared errors (MSE)}


MSE computes the average of the squares of the errors between the observed value $\left(\mathrm{S}_{\mathrm{obs}}\right)$ and the estimated value $\left(\mathrm{S}_{\text {cal }}\right)$.

$\operatorname{MSE}=\frac{1}{\mathrm{~N}} \sum_{\mathrm{i}=1}^{\mathrm{N}}\left(\mathrm{S}_{\mathrm{obs}}-\mathrm{S}_{\mathrm{cal}}\right)^{2}$

where, $\mathrm{N}=$ total number of data points predicted, $\mathrm{S}_{\mathrm{obs}}=$ observed value of relative permittivity, $\varepsilon_{\mathrm{b}}$ and $\mathrm{S}_{\mathrm{cal}}=$ calculated value of relative permittivity, $\varepsilon_{b}$.

\section{Coefficient of Correlation $\left(\mathrm{R}^{2}\right)$}

The mathematical representation of coefficient of correlation is expressed in eq. (3).

The mathematical representation of coefficient of correlation is expressed in eq. (3).

$$
R^{2}=1-\frac{\sum\left(Y_{\text {measured }}-Y_{\text {pred }}\right)^{2}}{\sum\left(Y_{\text {measured }}-\frac{\sum Y_{\text {measured }}}{N}\right)^{2}}
$$

where, $Y_{\text {pred }}$ is the network prediction value, $Y_{\text {measured }}$ is the experimental response value and $N$ is the total number of reading in the data points.

\section{Results And Discussions}

The results of the above investigations are presented and discussed in the following subsections.

\section{ANN Models}

As stated earlier, different configurations of the ANN models were tested to effectively and efficiently predict the carbonation efficiency of mineral rocks based on the mineralogical and chemical compositions of the rock materials. This testing of different configurations is necessary to ensure that the most reliable ANN structure is applied to learn the trends and relationships in the range of data used. The well-trained ANN model, having the best performance criteria, can then be used to predict the 
carbonation efficiency values applicable to the cases and conditions of interest. Therefore, this subsection presents the results of the training, validation and testing, as well as the performances of the different ANN model configurations. Out of all the configurations tested in this study, the comparisons of the Coefficient of Correlation $\left(\mathrm{R}^{2}\right)$ and Mean Squared Error (MAE) show that the ANN model with ANN[174-1] has the best performance. This model has only 4 neurons in the single hidden layer. The procedure followed in these comparisons was similar to the one described in the work of Abidoye et al. (2018).

In this work, discussion is limited to the best-performing configuration (ANN-[17-4-1]) to save space and time of the readers. The performances in training, validation and testing as well as the post-training regression for the best-performing ANN configuration is shown in Figures 1 and 2 . As shown in figure 1, the performance during the training shows gradual learning of the trend in the data and the effective prediction of the output, resulting in gradual reduction in error (MSE) as the epoch number increases. The validation process shows that the network has grabbed the relationship among the data and the output without tending to overfit. This culminated in the optimal error value of $8.73 \times 10^{-3}$ at the $23^{\text {rd }}$ epoch.

The effect of good training and learning is further reflected in the regression output of the network. This is shown Figure 2, where the correlation coefficient is greater than $99 \%$. This points to the fact the network really learns and adapts the data well. Thus, the ANN[17-4-1] is suitable for predicting and forecasting the carbonation efficiency of mineral rocks based on the mineralogical and chemical compositions of the rock materials as well as the other experimental parameters. Other configurations perform less in in terms of the criteria of evaluation (MSE and $\mathrm{R}^{2}$ ). Therefore, this well-trained network was used to predict the influences of different parameters on the carbonation efficiency.

\section{Carbonation Efficiency}

Figure 3 shows the prediction of the experimental outputs by the best-performing ANN configuration (ANN[17-4-1]). The figure shows good matches of the original experimental outputs (carbonation efficiencies) at most of the points. In fact, in most of the points, the predicted outputs wholly overlayed the original experimental outputs. In the remaining points, it is visually evident that the ANN predictions provide over $99 \%$ coverage of the original experimental output values. This corresponds to the correlation coefficient of above 0.99 , shown in Figure 2. Thus, the network model used in this work is a highly efficient one to predict the output of carbonation process. As stated earlier, this study will be among the first set of publications, in the open literature, to utilize the concept of machine learning to predict and forecast the carbonation efficiency of rock materials based on the material contents and experimental conditions.

\section{Effects of particle sizes}

Figure 4 shows the behaviour of carbonation efficiency with change in particle sizes. It can be seen that the efficiency becomes lower as the particle size increases. The efficiency at the original particle size 
remains the highest. The efficiency starts to diminish at $10 \%$ increase in the experimental size of the particles and more so at 20 and $30 \%$ particle size increases with respect to the original experimental (original) particle size.

Maximum effects of size change show up to 88,180 and $289 \%$ reductions in carbonation efficiency corresponding to 10,20 and $30 \%$ particle size increases, respectively, which occur at the data count of 113. Close to that were $91,184,277 \%$ reductions in carbonation efficiency corresponding to 10,20 and $30 \%$ particle size increases, respectively, which occur at the data count of 186 . Significantly high effects of particle size were also felt at data counts of 116,129 and 161 with 271, 265 and $267 \%$ reduction in carbonation efficiency, respectively, at $30 \%$ rise in particle size. It is interesting to note that these most significant effects on particle size on carbonation efficiency, are related to time or period of carbonation. The above results occur at carbonation time less than or equal to $1 \mathrm{hr}$.

At higher carbonation time, say $2 \mathrm{hrs}$., lesser effect of particle size was recorded. For example, at the data count of 130 , for $2 \mathrm{hrs}$ carbonation time, maximum of $149 \%$ reduction was found in carbonation efficiency, corresponding to $30 \%$ increase in particle size. At $3 \mathrm{hrs}$ carbonation time, like that at data count of 170 , the maximum reduction in carbonation efficiency was $55 \%$, occurring at $30 \%$ increase in particle size. Also, for 5 hrs carbonation period, the maximum efficiency reduction was $44 \%$, occurring at data count of 172 .

Above discussions show the interconnections between carbonation efficiency, particle size and carbonation time. Particularly, it shows strong negative correlations between efficiency and particle size. It further highlights that the effects of particle size on carbonation efficiency can be overcome or, at least, reduced, by prolonging the duration of the carbonation.

Wang et al. (2019) found that the smaller particle size $(0-25 \mu \mathrm{m})$ significantly enhances the carbonation efficiency. Yan et al. (2015) found that using smaller particle sizes of feedstock is more favorable to carbonation reaction.

\section{Effects of Calcium}

Figure 5 shows the pattern of carbonation efficiency with changing percentages of calcium in the mineral. Largely, the \% of calcium correlates positively with the carbonation efficiency. Maximum effect of calcium was found to be $344 \%$ rise in carbonation efficiency at $10 \%$ increase in the percentage of calcium. This occurs at data count of 222 in Figure 5. Further increase in the amount of calcium to 20 and $30 \%$ reduces the effect on carbonation to 318 and $286 \%$, respectively. Similar behaviour was noticed at the data count of 237, where the maximum effect of calcium on efficiency was found to be $248 \%$ at $10 \%$ increase in calcium amount. This reduces to 246 and $243 \%$ upon further increase in calcium amount. 
The above goes to show that there is optimum level of increase in the calcium amount to yield increased carbonation efficiency. Though, further increase in the calcium also yielded higher efficiency, with reference to the original level of the calcium in the mineral, but the marginal increase continue to decrease with higher \% of calcium.

Li et al. (2018) emphasized that the release of calcium or magnesium from the silicate minerals will serve a great effect on carbonation yield. This idea emanated from the natural carbonation process which involves the weathering of magnesium, calcium and iron oxide-based silicate minerals, which then transforms atmospheric $\mathrm{CO}_{2}$ into carbonate minerals (Lackner 2003). The abundance of $\mathrm{Mg} / \mathrm{Ca}$-silicates on Earth offers enormous capacity for sequestering $\mathrm{CO}_{2}$ (Lackner et al. 1995). Thus, calcium component of the minerals has great and positive influence on the efficiency of the carbonation.

\section{Effects of silica on carbonation efficiency}

Similar to calcium, silica has positive correlation to carbonation efficiency. The highest effect on efficiency was $508 \%$ at $30 \%$ increase in the amount of silica, at the data count of 221 . Unlike calcium, silica maintains gradual rise in efficiency as the \% of silica increases. Thus, 234,400 and $508 \%$ were recorded respectively at 10,20 , and $30 \%$ increases in the amount silica, at data count 221 . According Lackner (1995), the abundance of $\mathrm{Mg} / \mathrm{Ca}$-silicates on Earth offers enormous capacity for sequestering $\mathrm{CO}_{2}$. Mineralogical components of the samples helped in the formation of carbonates due to the presence of $\mathrm{Ca}$ - and $\mathrm{Mg}$-silicate minerals such as anorthite, wollastonite, diopside, and johannsenite, alongside Fe oxide such as magnetite (Ramli et al., 2021)

\section{Effect of iron}

The presence of iron bears strong positive correlation with carbonation efficiency in most of the cases considered in this study. This is shown in Figure 7. Also, there is monotonous increase in the efficiency as the iron content of the mineral increases. The highest predicted performance was recorded as $1541 \%$ at $30 \%$ increase in iron content. This has exceeded the performance of all the mineral contents so far. At 10 and $20 \%$ rises in calcium content, 526 and 1039\% changes in efficiency were recorded, respectively. This occurred at data count 217 in Figure 7. What can be inferred from the results are the complex interplay of fractional composition of the mineral contents. For example at data count 221 in Figure 7 , where conditions are similar to that at the count 217 , the highest performance recorded was $674 \%$ at $30 \%$ rise in iron content. Upon close inspection, the discrepancy was attributed to the relatively higher level of magnesium in the former (data count 217). This seems to reveal the complex interrelationship between the fractional composition of mineral content and carbonation efficiency. Ramli et al. (2021) found that iron mining waste was influential in determining carbonation efficiency.

\section{Effects of pH}


The effect of $\mathrm{pH}$ on carbonation is shown in Figure 8. The pattern of the plot shows the non-monotonic trend in the change of efficiency with change in $\mathrm{pH}$ of the system. The highest positive changes in efficiency were $1099 \%$ and $1092 \%$ recorded at $30 \%$ increase of $\mathrm{pH}$, for the data counts 199 and 36, respectively. Contrarily, the efficiency becomes reduced upon increase in $\mathrm{pH}$ under certain conditions. Some of these scenarios are found at data count 217,220 , etc., with 1873 and $1462 \%$ reduction in the efficiency, respectively, at $30 \%$ rise in $\mathrm{pH}$ value. Critical inspection shows that interplay of temperature and pressure plays prominent role in these behaviours. It was found that high temperature $\left(>100^{\circ} \mathrm{C}\right)$ combined with high pressure ( $>10$ bars) favours increased efficiency with rise in $\mathrm{pH}$ rise. Similarly, low temperature $\left(<100^{\circ} \mathrm{C}\right)$ with low pressure ( $<10$ bars) increased efficiency with rise in $\mathrm{pH}$ rise. On the contrary, low pressure with high temperature yields reverse trends in efficiency. These are the cases for data counts at 217, and 220 as well as other similar other points. Ramli et al. (2021) found positive correlation between carbonation efficiency and the $\mathrm{pH}$. But the authors did not investigate the complex interplay of this behaviour with temperature. $\mathrm{Mg}$-silicate minerals such as forsterite $\left(\mathrm{Mg}_{2} \mathrm{SiO}_{4}\right)$ and serpentine group minerals $\left[\mathrm{Mg}_{3} \mathrm{Si}_{2} \mathrm{O}_{5}(\mathrm{OH})_{4}\right]$ have $\mathrm{pH}$-dependent dissolution rates that are much faster than other silicate minerals (Li et al. 2018)

\section{Effects of stirring}

Stirring maintains positive influence on carbonation efficiency under different conditions. The largest positive effect of stirring was recorded at $222^{\text {nd }}$ data count where carbonation efficiency rises up by 377,386 and $394 \%$ upon increase of the stirring speed by 10,20 and $30 \%$ respectively. Up to 217,251 and $252 \%$ increases in efficiency were recorded at $202^{\text {nd }}, 227^{\text {th }}$ and $237^{\text {th }}$ data counts, respectively. The points showing high positive influences of stirring on efficiency are all corresponding to low original carbonation efficiencies, with values around $1 \%$ or less of carbonation. This goes to show that stirring of the mixture will impact most the original low-efficiency process. In contrast, the originally high efficiency records low marginal increase in carbonation level with increase in stirring speed. For example, at $100^{\text {th }}$ data count, with initial carbonation efficiency of $29 \%$, only $23 \%$ marginal increase was recorded upon $30 \%$ change in stirring speed. At original $36 \%$ carbonation, only $23 \%$ increase was maximally recorded at $30 \%$ rise in stirring speed. This shows the veracity of the claim that low-efficient carbonation process can always be upscaled by increasing the speed of stirring or mixing. By increasing mixing speed, this gives room for the exposure of more surface area to facilitate more reaction. It also give force to the movement of the gas $\left(\mathrm{CO}_{2}\right)$ to dive more into the matrices of the particulates to raise the reaction activity. This has tendency to improve reaction in less-efficient process. Wang et al. (2019) found that the efficiency of carbonation increases with stirring speed.

\section{Effects of pressure}

Figure 10 shows that the pressure mainly has positive influences on the carbonation efficiency. Up to $490 \%$ rise efficiency was recorded at the $30 \%$ increase in pressure. This was recorded at the original 
efficiency of $2.7 \%$ carbonation. 426,432 and $368 \%$ rises in carbonation, were recorded at the original efficiencies of $11,9.5$ and $0.9 \%$, respectively. This shows that, unlike in stirring speed (Figure 9), influence of pressure was independent of the initial value of efficiency.

\section{Effects of carbonation time}

Plot of influences of changes in carbonation time on the efficiency of carbonation is shown in figure 11. The carbonation time maintains positive influences on carbonation as the time of carbonation increases. Up to $375 \%$ increases in carbonation was recorded upon $30 \%$ rise in carbonation time. Scrutiny shows that the influence of time has relation with initial carbonation performance. For example, 375, 248, and $216 \%$ increases in efficiency were recorded for the initial experimental $0.9,0.65$ and $0.69 \%$ carbonation levels, respectively. In comparison, only 20, 22 and $23 \%$ increases were recorded upon initial efficiencies of 66,40 and $10 \%$, respectively. This clearly indicates that change in carbonation time will mostly impart the low-efficiency carbonation process.

\section{Effects of temperature}

Rising temperature majorly have positive influence on the efficiency of the carbonation. Up to $755 \%$ increase in efficiency was recorded by raising the temperature by $30 \%$. This occurs at the experimental efficiency level of $8 \%$. At around $10-11 \%$ of original efficiency, ANN predicted close to $600 \%$ rise in carbonation level. Interesting trend was noticed in predicted efficiency based on the original experimental carbonation level. For example, at 15, 20, 34 and $48 \%$ original efficiencies, predicted levels of carbonation were 196, 140, 47 and $13 \%$, respectively, at $30 \%$ rise in temperature.

Curiously, at very high original carbonation efficiency, e.g., above $50 \%$, reverse trend was predicted by the ANN model. This may mean that at very high carbonation level, it is of no benefit to raise the temperature further, as this may lead to decarbonation of the medium. Or, raising the temperature may destabilize the carbonate phase, increase buoyancy of the absorbed $\mathrm{CO}_{2}$ and leads to desorption.

\section{Conclusion}

Influences of mineralogical and chemical constituents of sample rocks on carbonation efficiency have been numerically investigated, using machine learning technique with single-layer ANN configurationANN[17-4-1]. The carbonation efficiency becomes lower as the particle size increases with maximum effects of size change show up to 88,180 and $289 \%$ reductions in carbonation efficiency corresponding to 10, 20 and 30\% particle size increases, respectively. There are interconnections between carbonation efficiency, particle size and carbonation time. Particularly, there are strong negative correlations between efficiency and particle size. But, this study further highlights that the effects of particle size on carbonation efficiency can be overcome or, at least, reduced, by prolonging the duration of the carbonation. The study shows that there is optimum level of increase in the calcium amount to yield 
increased carbonation efficiency, following which the marginal increase in $\%$ of calcium continue to result in decrease of efficiency. Unlike calcium, silica maintains gradual rise in efficiency as the $\%$ of silica increases. Thus, 234, 400 and $508 \%$ were recorded respectively at 10, 20, and $30 \%$ increases in the amount silica. Owing to relatively higher level of magnesium in the sample, ANN predicted performance of up to $1541 \%$ rise in efficiency at $30 \%$ increase in iron content. Complex interrelationship between the fractional composition of mineral content and carbonation efficiency was detected. Furthermore, it was found that high temperature $\left(>100^{\circ} \mathrm{C}\right)$ combined with high pressure ( $>10$ bars) favours increased efficiency with rise in $\mathrm{pH}$ rise. Similarly, low temperature $\left(<100^{\circ} \mathrm{C}\right)$ with low pressure $(<10$ bars $)$ increased efficiency with rise in $\mathrm{pH}$ rise. On the contrary, low pressure with high temperature yields reverse trends in efficiency. Pressure, carbonation time and temperature all have positive effects on carbonation efficiency. But, the carbonation time mostly imparts the low-efficient carbonation process. Also, unlike in stirring speed effect, influence of pressure was independent of the initial value of efficiency. On

temperature effect, curious inspection shows that, at very high original carbonation efficiency, e.g., above $50 \%$, reverse trend was predicted by the ANN model. This may mean that at very high carbonation level, it is of no benefit to raise the temperature further, as this may lead to decarbonation of the medium. Or, raising the temperature may increase buoyancy of the $\mathrm{CO}_{2}$ and leads to desorption. This study is the first or among the first set of publications, in the open literature, to utilize the concept of machine learning to predict and forecast the carbonation efficiency of rock materials based on material contents and experimental conditions

\section{References}

1. Abidoye LK, Mahdi FM, Idris MO, Alabi OO, Wahab AA (2018) ANN-Derived Equation and ITS Application in the Prediction of Dielectric Properties of Pure and Impure $\mathrm{CO}_{2}$. J Clean Prod. doi:10.1016/j.jclepro.2017.12.013

2. Abidoye LK, Das DB (2015) Artificial Neural Network (ANN) Modelling of Scale Dependent Dynamic Capillary Pressure Effects in Two-Phase Flow in Porous Media. J Hydroinformatics 17(3):446-461. doi:10.2166/hydro.2014.079

3. Akpinar P, Uwanuakwa FID (2016) Intelligent prediction of concrete carboration depth using neural networks. Bulletin of the Transilvania University of Brasov. Mathematics, Informatics, Physics. Series III, 9(2), p.99

4. Arpat GB, Gümrah F, Yeten B (1998) "The neighborhood approach to prediction of permeability from wireline logs and limited core plug analysis data using backpropagation artificial neural networks". J Petrol Sci Eng, 20(1-2), 1-8

5. Boroumand A, Baziar MH (2005) "Determination of Compacted Clay Permeability by Artificial Neural Networks". International Water Technology Conference, 9, pp. 515-525

6. Brian S, Freeman G, Taylor BG, Jesse Thé (2018) Forecasting air quality time series using deep learning. J Air Waste Manag Assoc 68(8):866-886. DOI:10.1080/10962247.2018.1459956 
7. Chowdhury A, Kautz E, Yener B, Lewis D (2016) Image driven machine learning methods for microstructure recognition. Comput Mater Sci 123:176-187

8. Gardner MW, Dorling SR (1998) Artificial neural networks (the multilayer perceptron) A review of applications in the atmospheric sciences. Atmos Environ 32(1415):2627-2636. doi:10.1016/S13522310(97)00447-0

9. Goodfellow I, Bengio Y, Courville A (2016) Deep Learning. Cambridge, MA: MIT Press. ISBN: 9780262035613

10. Hänsel MC, Drupp MA, Johansson DJ, Nesje F, Azar C, Freeman MC, Groom B, Sterner T (2020) Climate economics support for the UN climate targets. Nature Climate Change 10(8):781-789

11. Hanspal NS, Allison BA, Deka L, Das DB (2013) Artificial neural network (ANN) modeling of dynamic effects on two-phase flow in homogenous porous media. J Hydroinformatics 15(2):540-554. DOI:10.2166/hydro.2012.119

12. Haykin SS (2009) "Neural Networks and Learning Machines". 3rd edn. Pearson Education, Inc. Upper Saddle River, N.J. ISSN/ISBN. 13-978-0-13-129376-2

13. Huijgen WJJ, Witkamp G, Comans RNJ (2006) Mechanisms of aqueous wollastonite carbonation as a possible $\mathrm{CO} 2$ sequestration process. Chem Eng Sci 61:4242-4251. https://doi.org/10.1016/j.ces.2006.01.048

14. Itzel Nunez ML, Nehdi (2021) Machine learning prediction of carbonation depth in recycled aggregate concrete incorporating SCMs, Construction and Building Materials, Volume 287, 2021, https://doi.org/10.1016/j.conbuildmat.2021.123027

15. Li J, Hitch M, Power IM, Pan Y (2018) Integrated Mineral Carbonation of Ultramafic Mine Deposits-A Review Minerals 8:147. doi:10.3390/min8040147

16. Jean David LAU HIU HOONG, Jérôme LUX, Pierre-Yves MAHIEUX, Philippe TURCRY, Abdelkarim AÏTMOKHTAR (2020) Determination of the composition of recycled aggregates using a deep learningbased image analysis. DOI: 10.1016/j.autcon.2020.103204

17. Khataee AR, Kasiri MB (2010) "Artificial neural networks modeling of contaminated water treatment processes by homogeneous and heterogeneous nanocatalysis". J Mol Catal A: Chem 331(1-2):86100

18. Lackner K, Wendt C, Butt D, Joycejr E, Sharp D (1995) Carbon dioxide disposal in carbonate minerals. Energy 1995, 20, 1153-1170. [CrossRef]

19. Lackner KS (2003) A Guide to CO2 Sequestration. Science 2003, 300, 1677-1678. [CrossRef] [PubMed]

20. Li J, Hitch M, Power IM, Pan Y (2018) Integrated Mineral Carbonation of Ultramafic Mine Deposits-A Review. Minerals 2018, 8, 147; doi:10.3390/min804014

21. Liu P-WG (2007) Establishment of a Box-Jenkins multivariate timeseries model to simulate groundlevel peak daily one-hour ozone concentrations at Ta-Liao in Taiwan. J Air Waste Manage Assoc 57(9):1078-1090. doi:10.3155/1047-3289.57.9.1078 
22. Matter JM, Kelemen PB (2009) Permanent storage of carbon dioxide in geological reservoirs by mineral carbonation. Nat. Geosci. 2, 837-841. https://doi.org/10. 1038/ngeo683

23. Martinez RE, Weber S, Bucher K (2014) Quantifying the kinetics of olivine dissolution in partially closed and closed batch reactor systems. Chem Geol 367, 1-12. https:// doi.org/10.1016/j.chemgeo.2013.12.017

24. Nowroozi S, Ranjbar M, Hashemipour H, Schaffie M (2009) "Development of a neural fuzzy system for advanced prediction of dew point pressure in gas condensate reservoirs". Fuel Process Technol 90(3):452-457

25. 'Connor O, Dahlin WK, Rush DC, Gerdemann GE, Penner SJ, Nilsen LR, D.N., 2005. Aqueous Mineral Carbonation: Mineral Availability, Pretreatment, Reaction Parametrics and Process Studies. Albany Research Centre, DOE/ARC-TR-04-002 Albany, OR, USA

26. Pasquier LC, Mercier G, Blais JF, Cecchi E, Kentish S (2014) Reaction mechanism for the aqueousphase mineral carbonation of heat-activated serpentine at low temperatures and pressures in flue gas conditions. Environ Sci Technol 48:5163-5170. https://doi.org/10.1021/es405449v

27. Polettini A, Pomi R, Stramazzo A (2016) Carbon sequestration through accelerated carbonation of BOF slag: influence of particle size characteristics. Chem Eng J 298:26-35. https://doi.org/10.1016/j.cej.2016.04.015

28. Ramli NAA, Kusin FM, Molahid VLM (2021) Influencing Factors of the Mineral Carbonation Process of Iron Ore Mining Waste in Sequestering Atmospheric Carbon Dioxide. Sustainability 2021, 13, 1866. https://doi.org/10.3390/su13041866

29. Saeedi A, Camarda KV, Liang TJ (2007) "Using Neural Networks for Candidate Selection and WellPerformance Prediction in Water-Shutoff Treatments Using Polymer Gels-A Field-Case Study". SPE Prod Oper 22(4):417-424

30. Shetty GR, Chellam S (2003) Predicting membrane fouling during municipal drinking water nanofiltration using artificial neural networks. J Membr Sci 217:69-86

31. Ukwattage NL, Ranjith PG, Li X (2017) Steel-making slag for mineral sequestration of carbon dioxide by accelerated carbonation. Meas J Int Meas Confed 97:15-22

32. Uwanuakwa ID (2021) Deep Learning Modelling and Generalisation of Carbonation Depth in Fly Ash Blended Concrete. Arabian Journal for Science Engineering 46(5):4731-4746

33. Taffese WZ, Sistonen E, Puttonen J (2015) Prediction of concrete carbonation depth using decision trees. In Proceedings of 23rd European Symposium on Artificial Neural Networks, Computer Intelligence Machine Learning (pp. 415-420)

34. Sanna A, Uibu M, Caramanna G, Kuusik R, Maroto-Valer MM (2014) A review of mineral carbonation technologies to sequester CO2. Chem Soc Rev 43:8049-8080. https://doi.org/10.1039/c4cs00035h

35. Song K, Kim W, Park S, Bang JH, Jeon CW, Ahn JW (2016) Effect of polyacrylic acid on direct aqueous mineral carbonation of flue gas desulfurization gypsum. Chem Eng J 301:51-57. https://doi.org/10.1016/j.cej.2016.04.142 
36. Sun J, Bertos MF, Simons SJR (2008) Kinetic study of accelerated carbonation of municipal solid waste incinerator air pollution control residues for sequestration of flue gas $\mathrm{CO} 2$. Energy Environ Sci 1:370-377. https://doi.org/10.1039/b804165m

37. Syed Hasan SNM, Mohd Kusin F, Jusop S, Mohamat Yusuff F (2018) Potential of soil, sludge and sediment for mineral carbonation process in Selinsing gold mine, Malaysia. Minerals, 8(6), p.257

38. Vlachogianni A, Kassomenos P, Karppinen A, Karakitsios S, Kukkonen J (2011) Evaluation of a multiple regression model for the forecasting of the concentrations of NOx and JOURNAL OF THE AIR \& WASTE MANAGEMENT ASSOCIATION 885PM10 in Athens and Helsinki. Sci Total Environ 409(8):1559-1571. doi:10.1016/j.scitotenv.2010.12.040

39. Wang D, Lu W-Z (2006) Ground-level ozone prediction using multilayer perceptron trained with an innovative hybrid approach. Ecol Modell 198(34):332-340. doi:10.1016/j.ecolmodel.2006.05.031

40. Wang F, Dreisinger DB, Jarvis M, Hitchins T (2018) The technology of CO2 sequestration by mineral carbonation: current status and future prospects. Can Metall Q 57:46-58. https://doi.org/10.1080/00084433.2017.1375221

41. Wang F, Dreisinger D, Jarvis M, Hitchins $T$ (2019) Kinetics and mechanism of mineral carbonation of olivine for CO2 sequestration. Minerals Engineering 131 (2019) 185-197. https://doi.org/10.1016/j.mineng.2018.11.024

42. Xi F, Davis SJ, Ciais P, Crawford-Brown D, Guan D, Pade C, Shi T, Syddall M, Lv J, Ji L, Bing L, Wang J, Wei W, Yang K-H, Lagerblad B, Galan I, Andrade C, Zhang Y, Liu Z (2016) Substantial global carbon uptake by cement carbonation. Nat Geosci 9:880-883. https://doi.org/10.1038/ngeo2840

43. Yan H, Zhang J, Zhao Y, Liu R, Zheng C (2015) CO2 sequestration by direct aqueous mineral carbonation under low-medium pressure conditions. J Chem Eng Jpn 48(11):937-946

44. Zabihi R, Schaffie M, Nezamabadi-pour H, Ranjbar M (2011) Artificial neural network for permeability damage prediction due to sulfate scaling. J Petrol Sci Eng 78:575-581

45. Zickus M, Greig AJ, Niranjan M (2002) Comparison of four machine learning methods for predicting PM10 concentrations in Helsinki, Finland. Water Air Soil Pollut Focus 2(5- 6):717-729. doi:10.1023/A:1021321820639

\section{Tables}

Due to technical limitations, Table 1 is only available as a download in the Supplemental Files section.

\section{Figures}




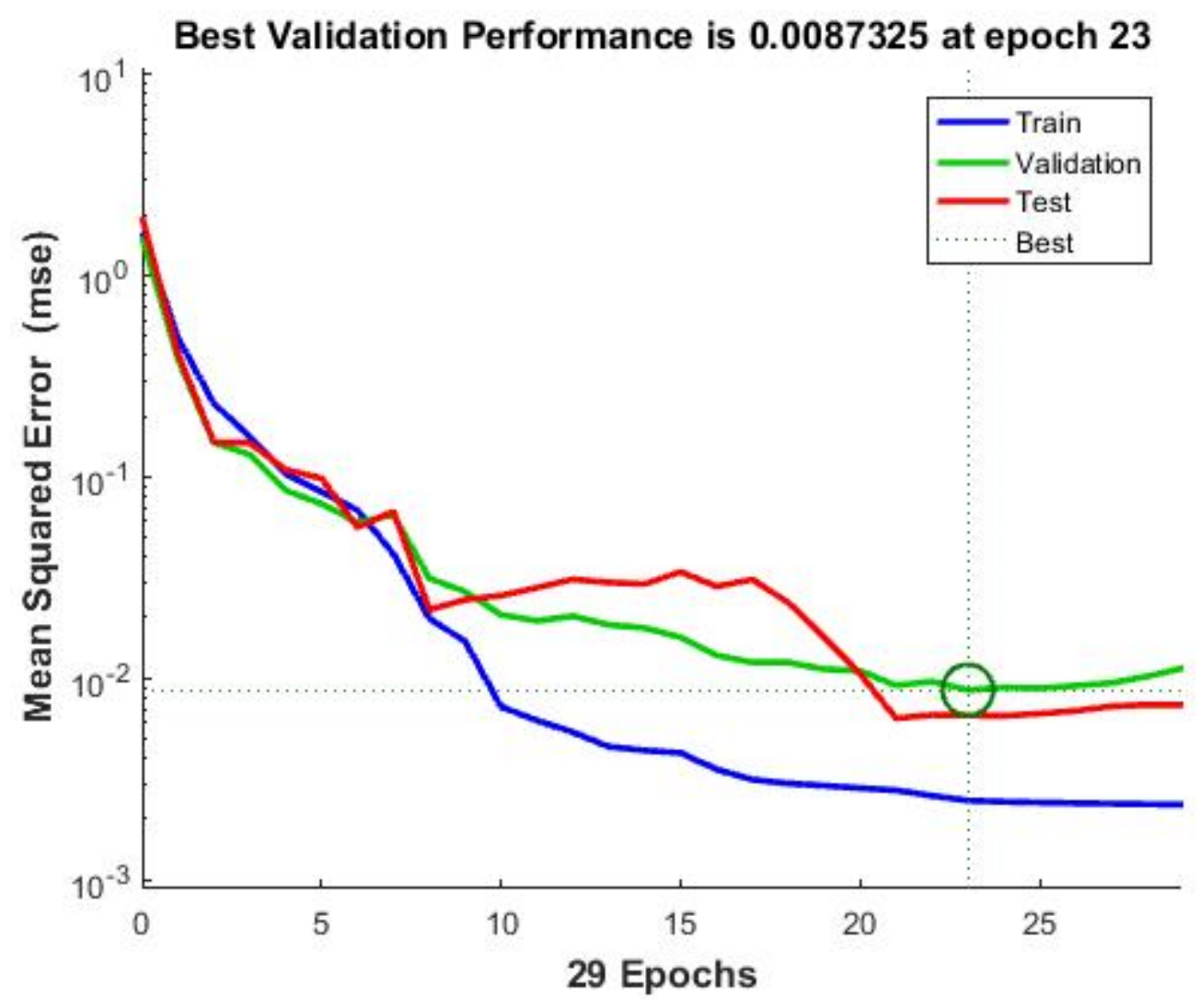

Figure 1

Performance of the ANN[17-4-1] model during Training, Testing and Validation processes. 


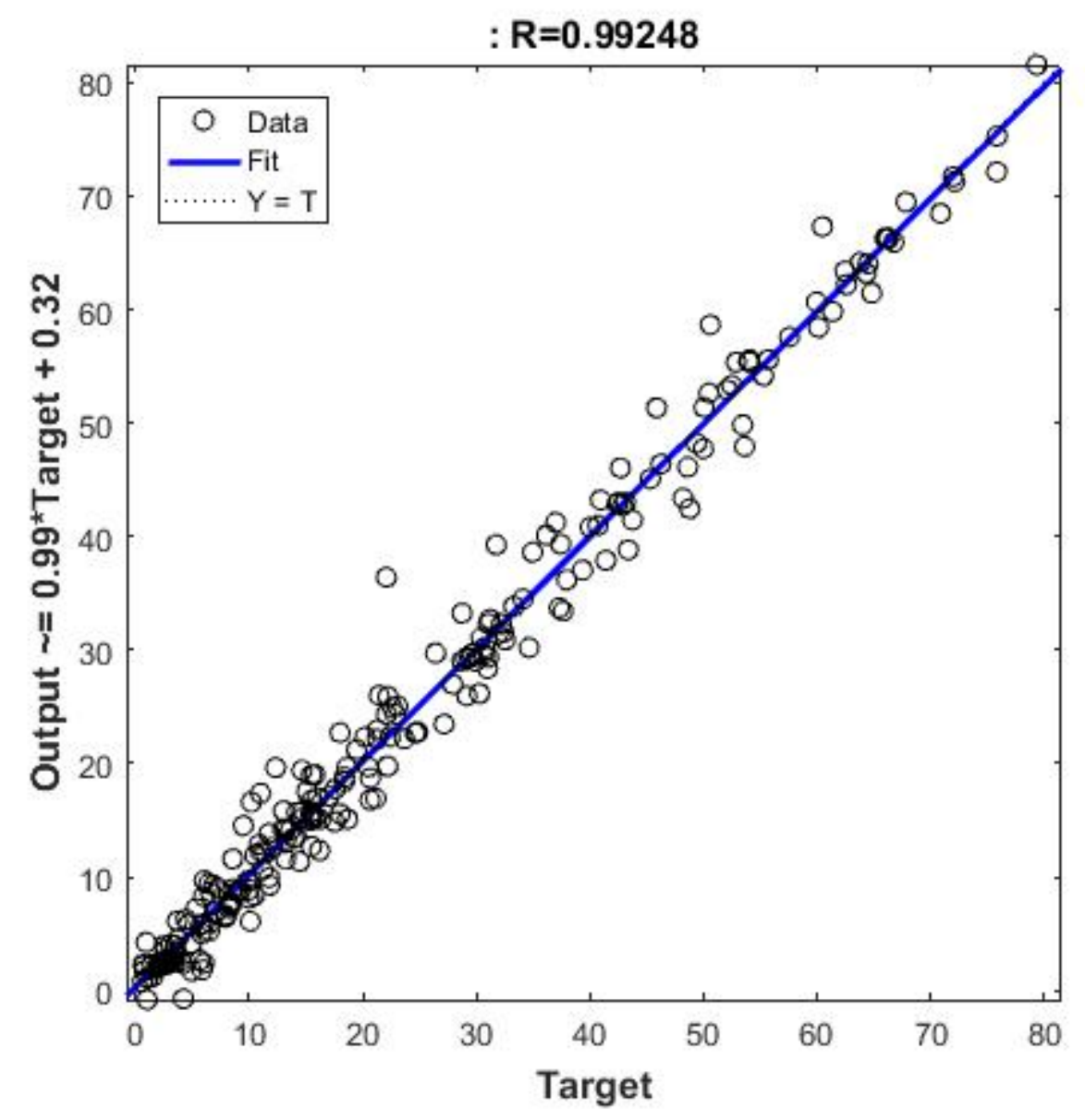

Figure 2

Regression analysis of the predicted and targeted outputs

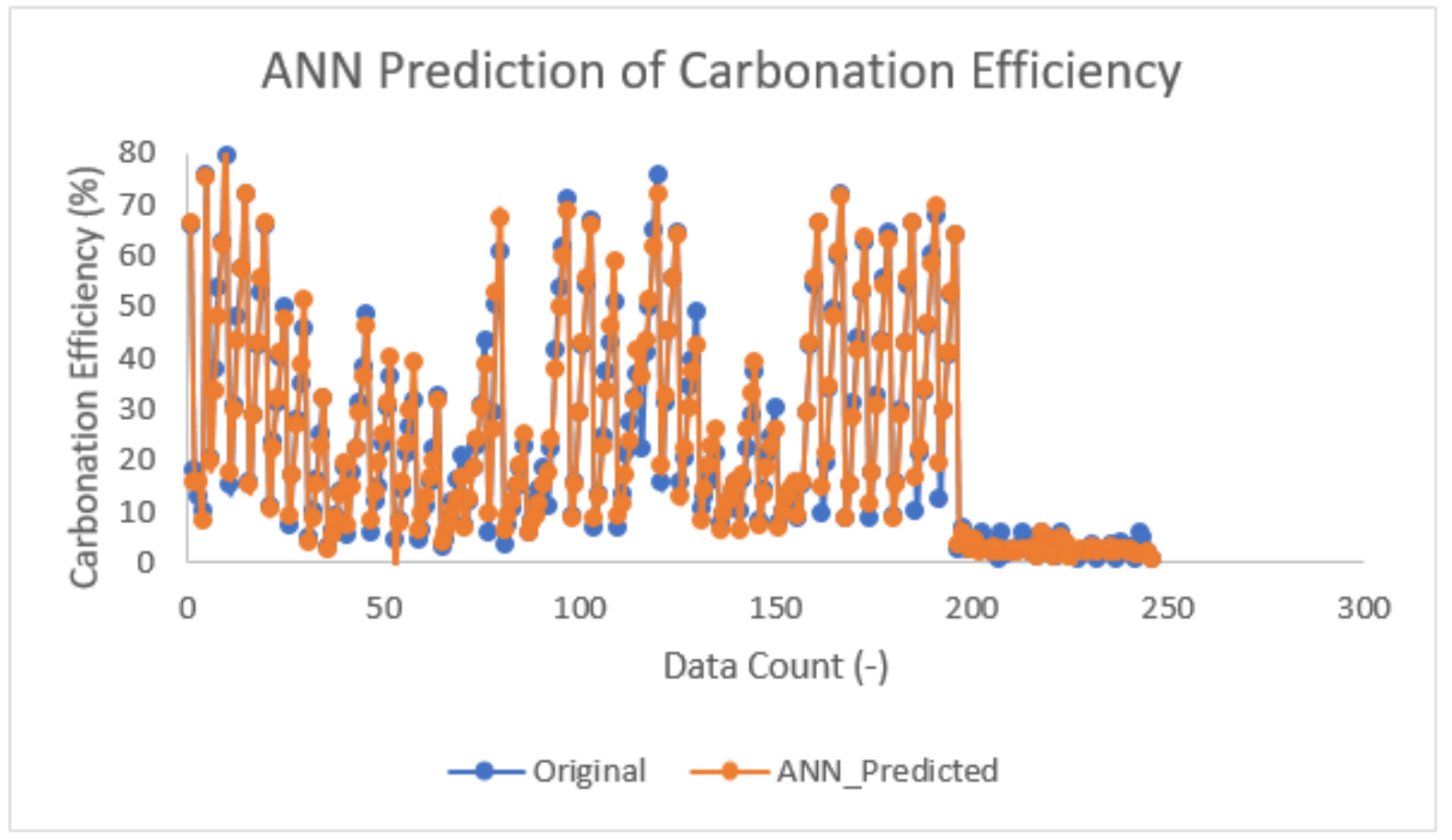


Figure 3

Prediction of the experimental efficiency data by the ANN

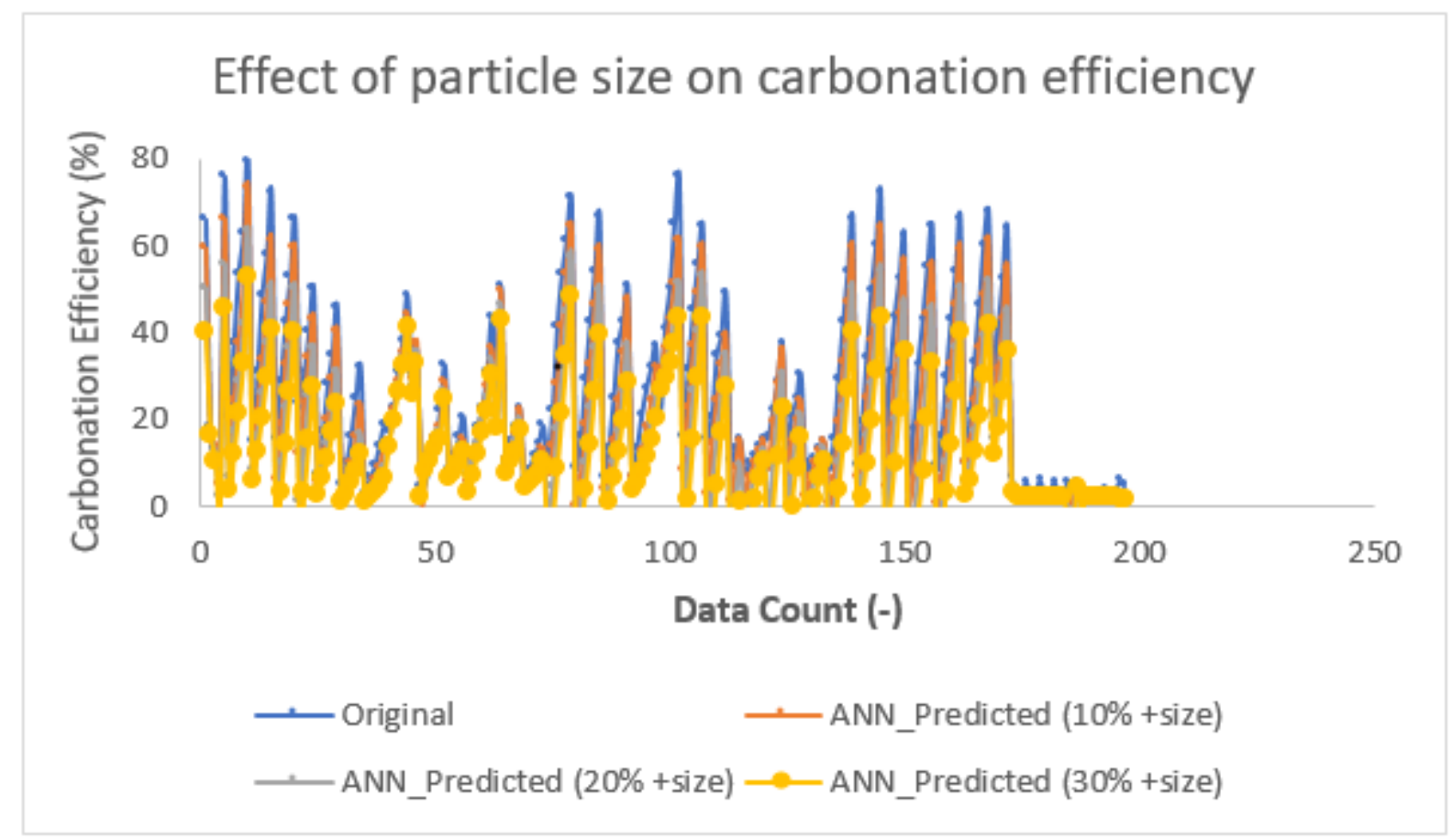

Figure 4

Carbonation efficiency with change in particle sizes.

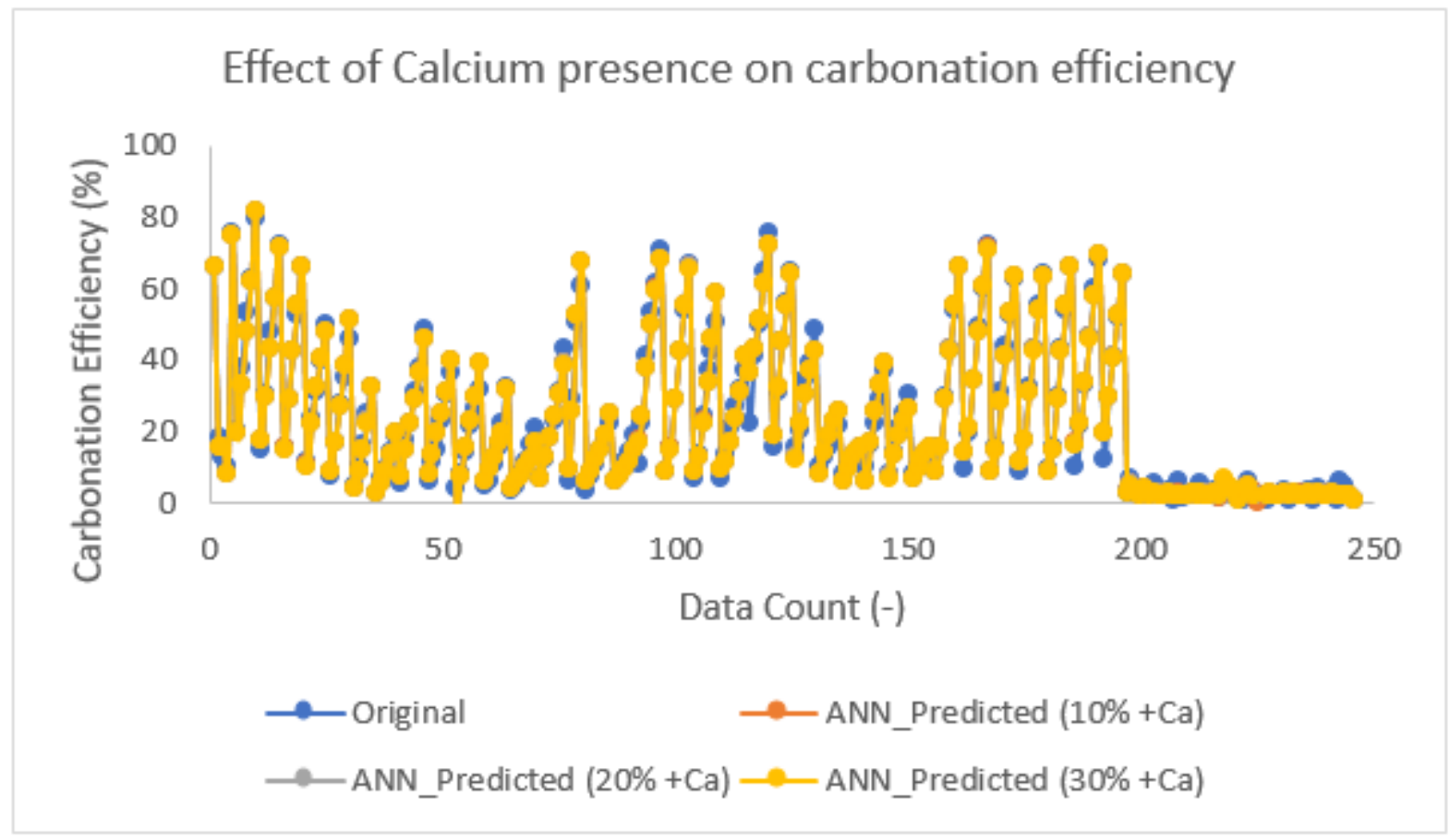

Figure 5 
Carbonation efficiency with change in $\%$ of calcium.

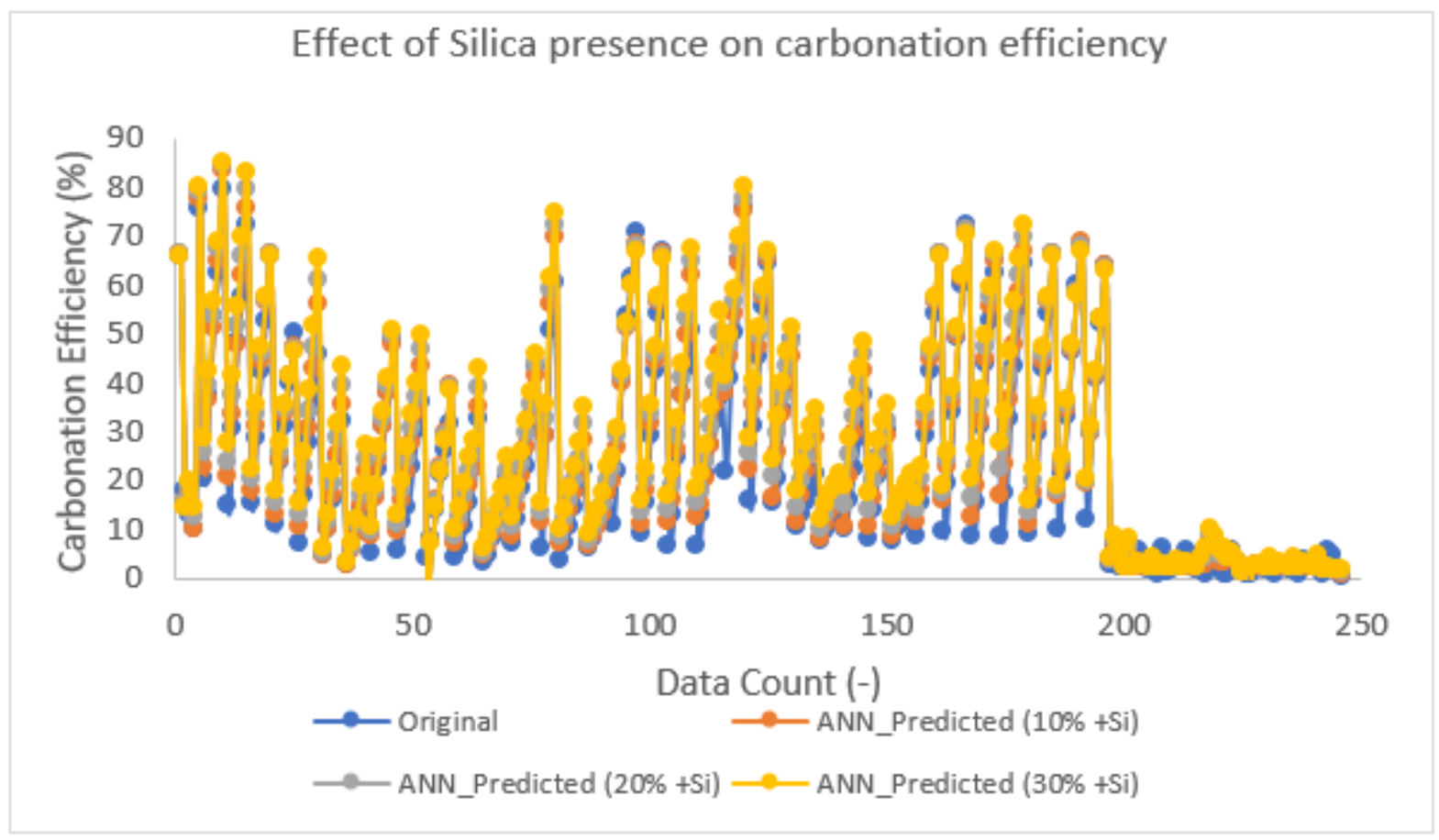

Figure 6

Carbonation efficiency with change in $\%$ of silica

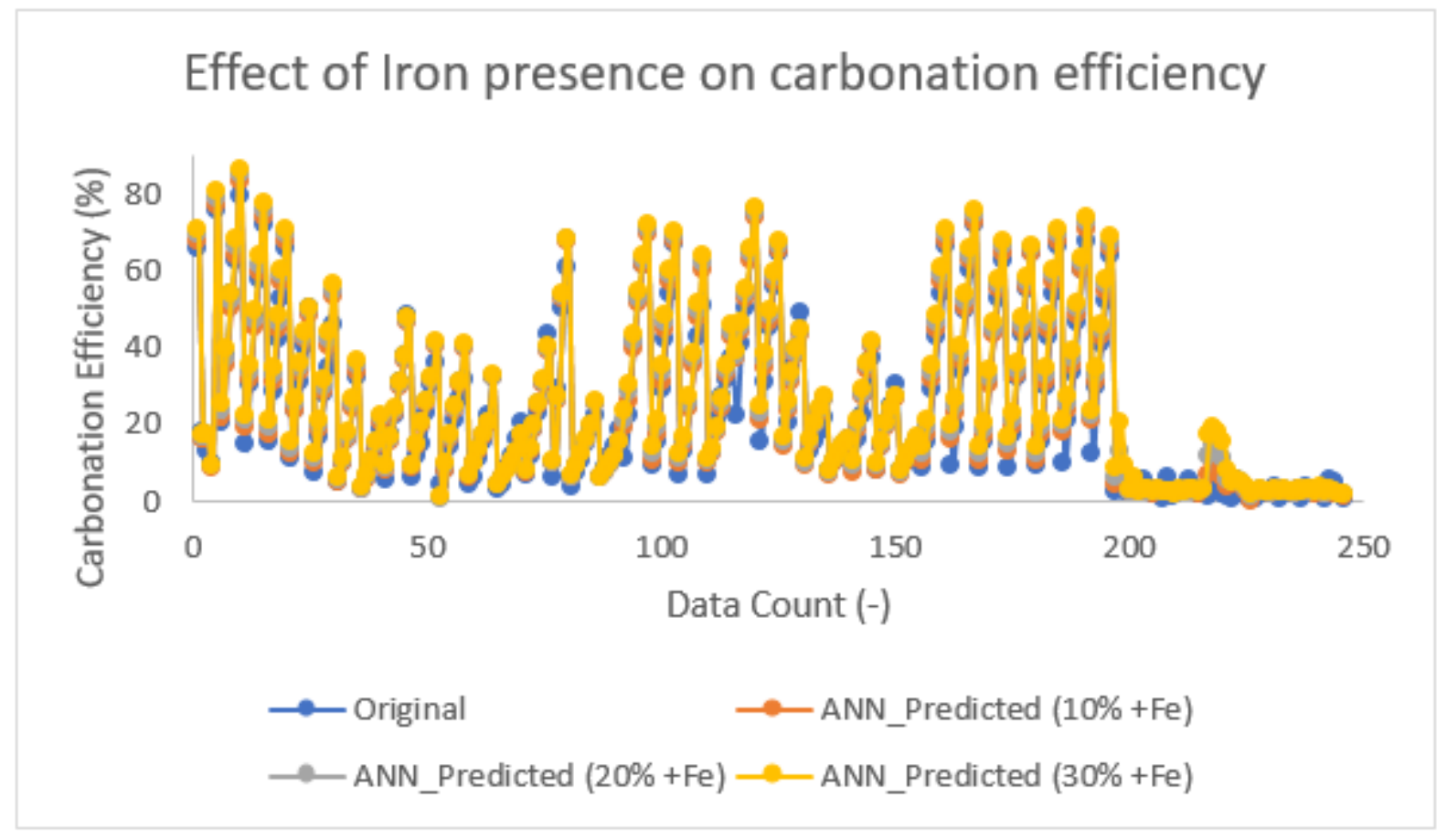

Figure 7

Carbonation efficiency with change in \% of iron 


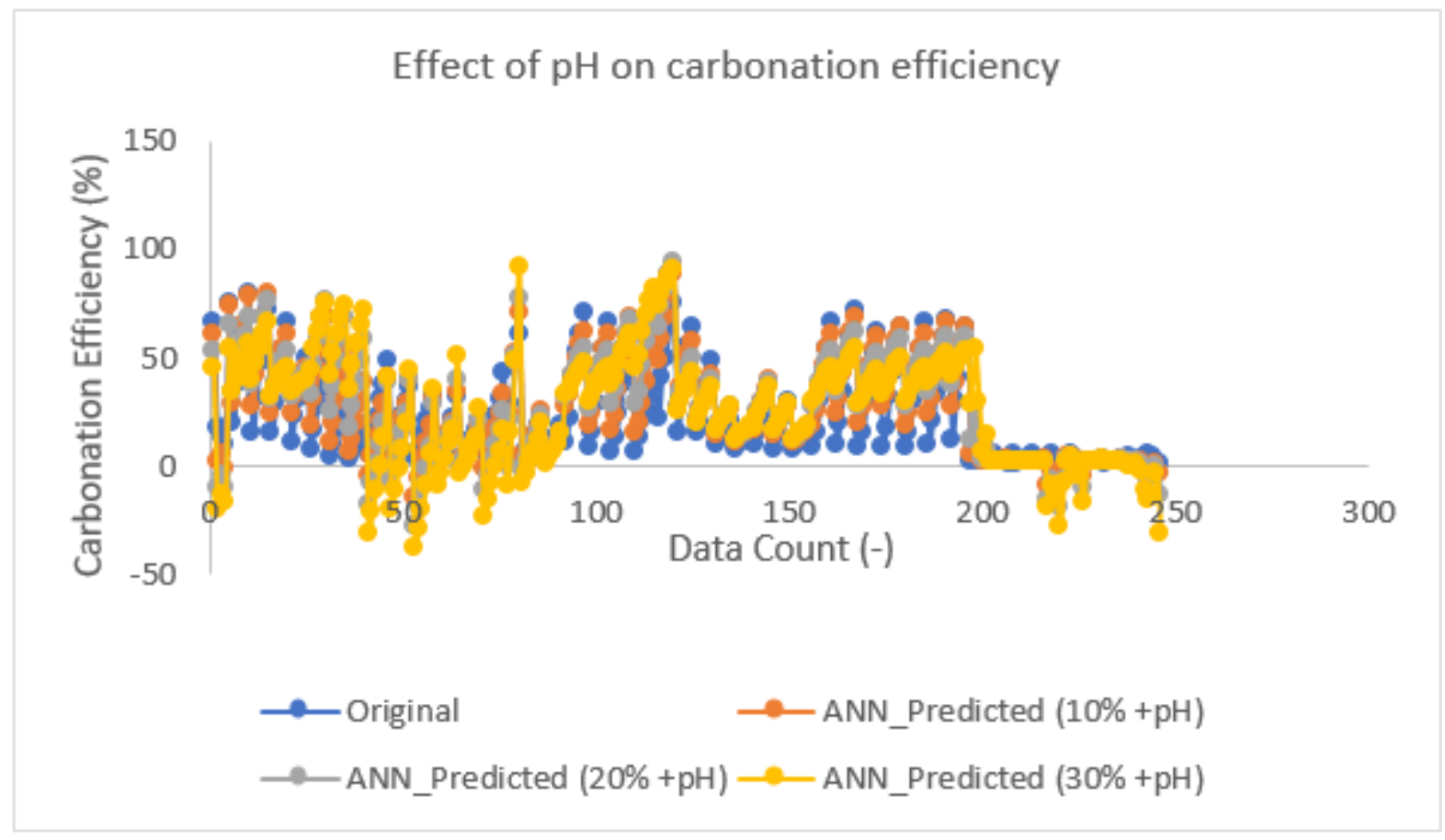

Figure 8

Carbonation efficiency with change in $\mathrm{pH}$

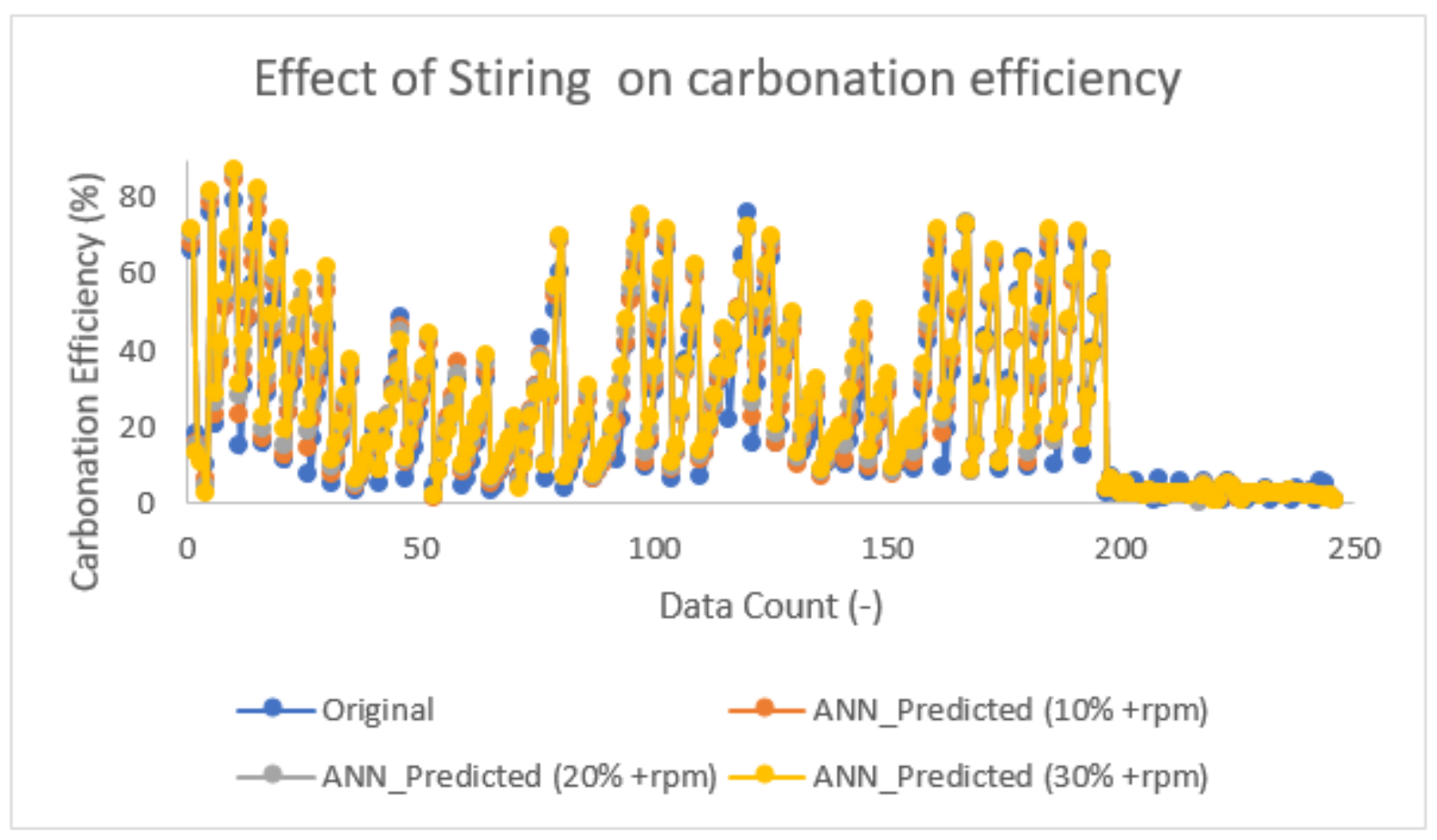

Figure 9

Carbonation efficiency with increase in stirring speed 


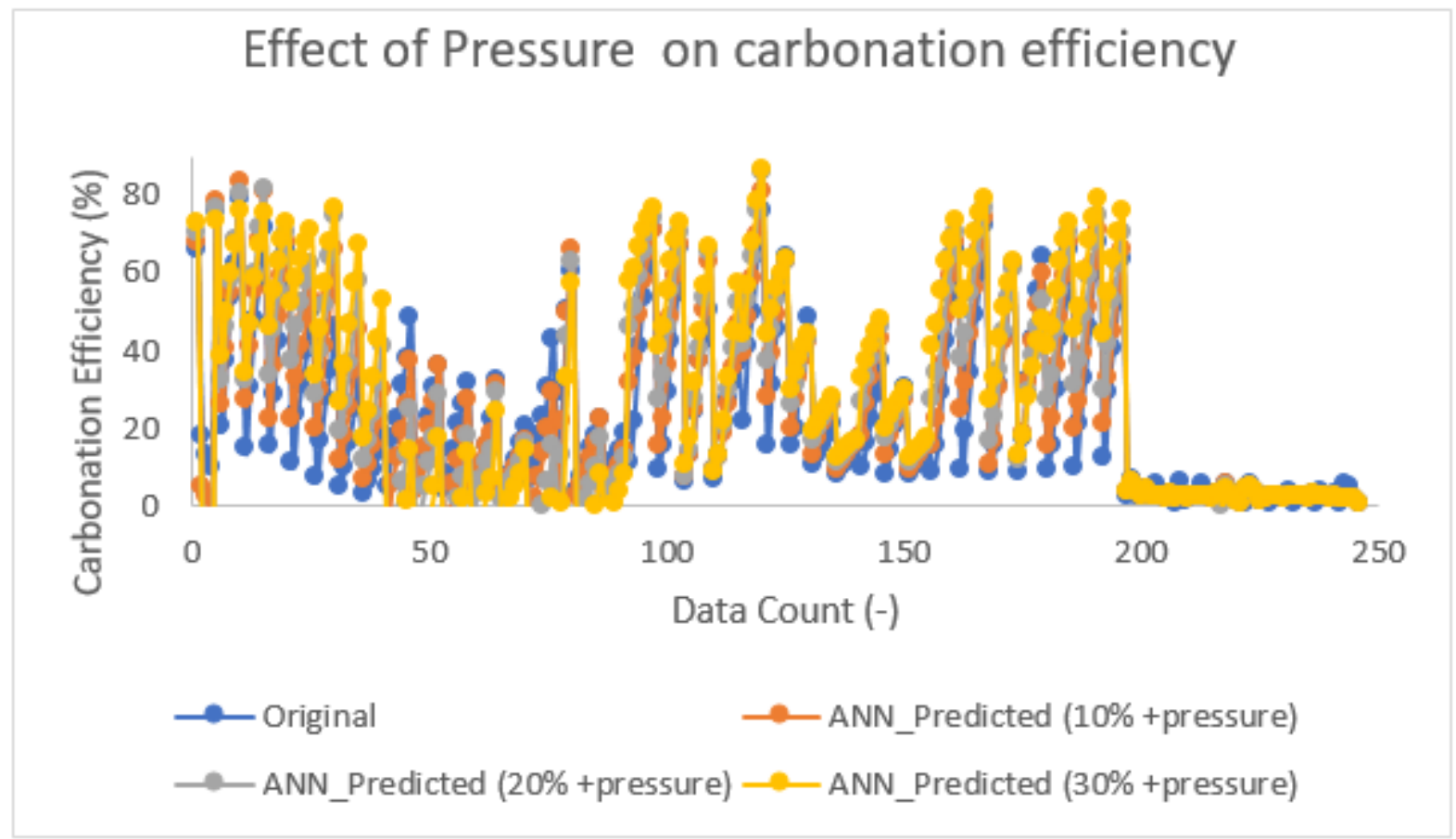

Figure 10

Effects of pressure on carbonation efficiency

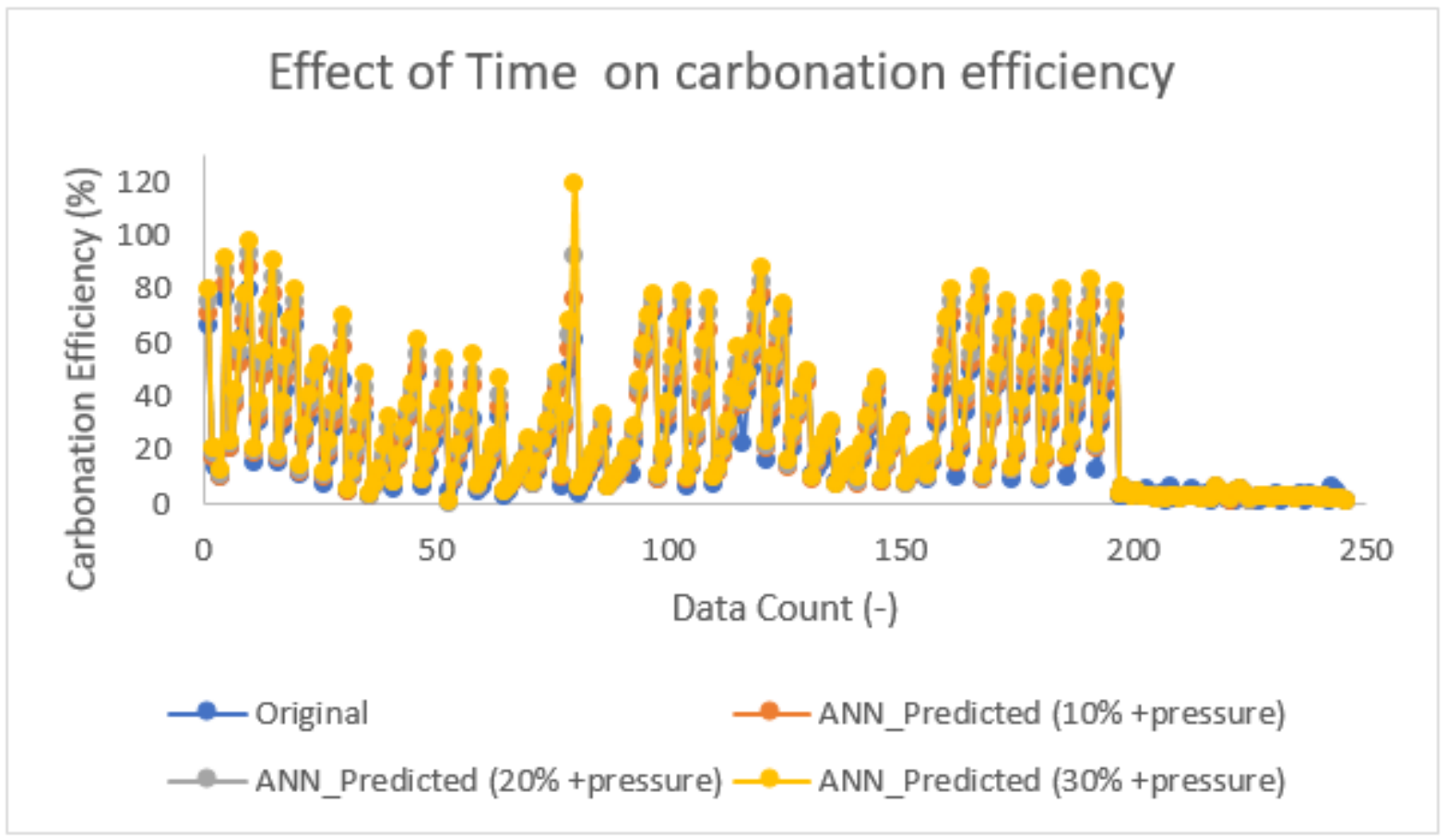

Figure 11

Effects of carbonation time on carbonation efficiency 


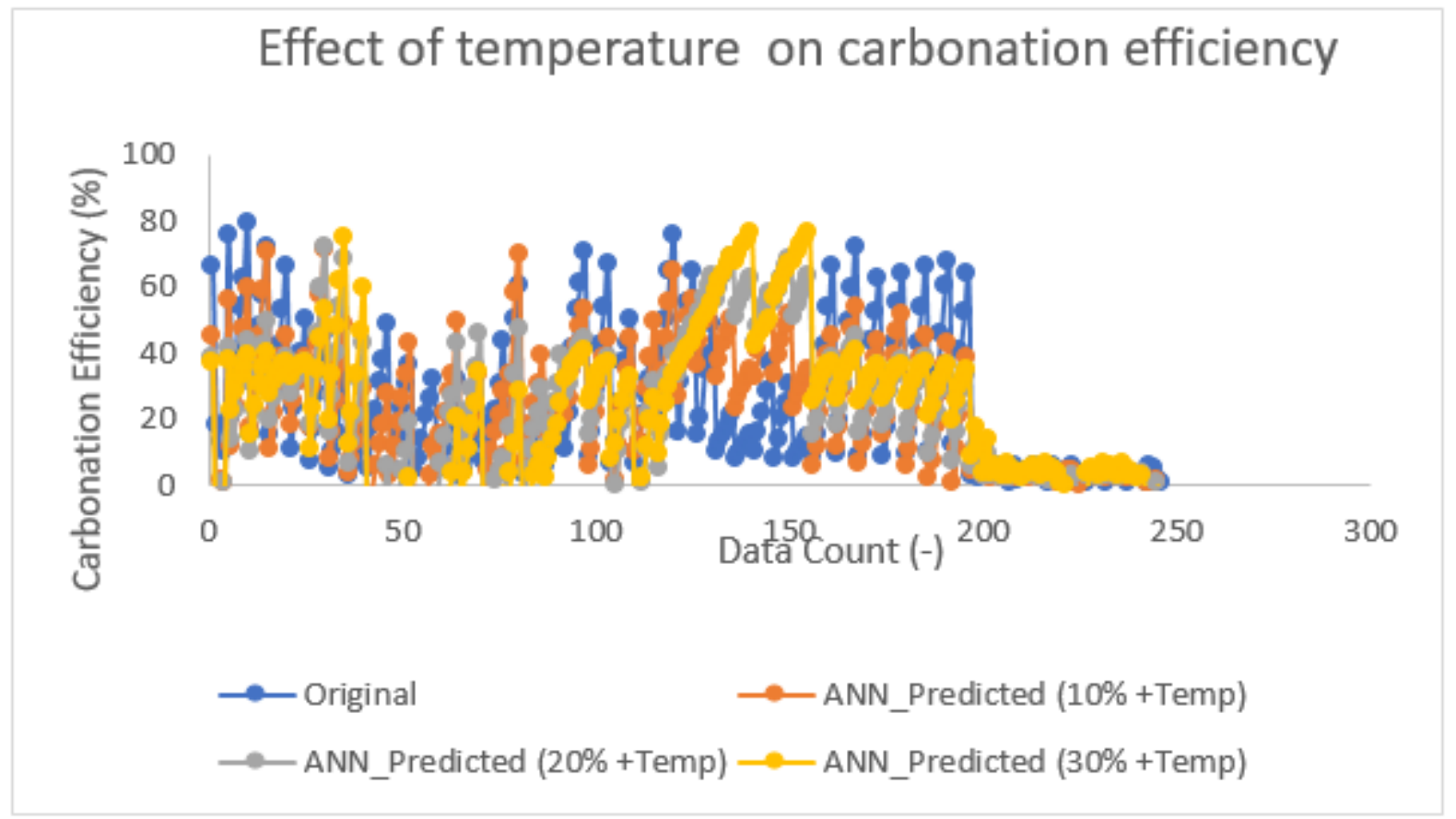

Figure 12

Effects of temperature increase on carbonation efficiency

\section{Supplementary Files}

This is a list of supplementary files associated with this preprint. Click to download.

- Table1Descriptivestatisticsoftheinputandoutputvariablesusedinthemachinelearning.docx 